Int. J. Electrochem. Sci., 14 (2019) $6431-6443$

\title{
The Breakdown of a 316L Stainless Steel Oxide Film in an $\mathrm{AlCl}_{3}$-EMIC Ionic Liquid
}

\author{
Jiani Huang, Zhehang Pan, Lun Jiang, and Guoping Ling* \\ School of Materials Science and Engineering, Zhejiang University, Hangzhou 310027, China \\ *E-mail: linggp@zju.edu.cn
}

doi: $10.20964 / 2019.07 .18$

Received: 10 February 2019 / Accepted: 20 April 2019 / Published: 10 June 2019

The breakdown of the oxide film on $316 \mathrm{~L}$ stainless steel was investigated in an acidic aluminum chloride-1-ethyl-3-methylimidazolium chloride $\left(\mathrm{AlCl}_{3}\right.$-EMIC) ionic liquid by linear sweep voltammetry, chronoamperometry and the pulse potentiostatic method. Scanning electron microscopy and atomic force microscopy were used to characterize the surface morphology. The results showed that the breakdown of the oxide film depended on the anodic dissolution potential, and the general breakdown occurred when the potential exceeded a critical potential. The general breakdown occurred instantaneously at a large number of positions all over the surface and was followed by a planar dissolution pattern. The oxide film remained on the surface after the general breakdown unless it was removed by stirring. The mechanism of the general breakdown of the oxide film and the subsequent planar dissolution pattern are discussed.

Keywords: Oxide film; General breakdown; Ionic liquid; Stainless steel; Electrochemical etching

\section{FULL TEXT}

(C) 2019 The Authors. Published by ESG (www.electrochemsci.org). This article is an open access article distributed under the terms and conditions of the Creative Commons Attribution license (http://creativecommons.org/licenses/by/4.0/). 